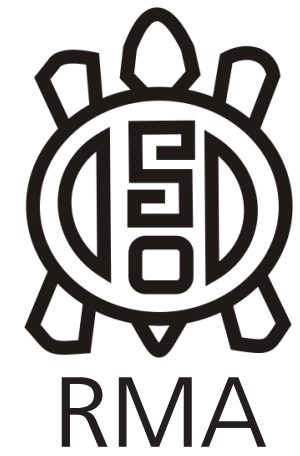

Museología

\title{
Un fortín que no es fortín, sino una casa y un museo llamado fortín. Patrimonio y memorias en la construcción de un relato sobre la frontera del sur bonaerense
}

\author{
A fort that is not a fort, but a house and a museum called a fort. \\ Heritage and memories in the construction of a story about the \\ southern frontier of Buenos Aires
}

Hernán Perrière*

*CONICET, Dpto. Humanidades, Universidad Nacional del Sur, Bahía Blanca, Argentina.

E-mail: hernanperriere@hotmail.com

\begin{abstract}
Resumen
En este artículo analizo los procesos de patrimonialización del Museo Fortín Cuatreros en el partido de Bahía Blanca (sur de la provincia de Buenos Aires) y los relatos históricos asociados como procesos de construcción de memorias locales y recurso educativo destinado a jóvenes de la escuela secundaria. Este museo representa el último de los fortines emplazados en el avance de la frontera que custodiaron a la llamada "Zanja de Alsina" en 1876, cercano a la ría que bordea dicha ciudad. En este artículo se despliegan en una primera parte, los distintos entramados que explican los sentidos otorgados al actual museo en perspectiva histórica (fundación, declaraciones patrimoniales, reconstrucciones) en diálogo con los relatos de pobladores pioneros de la localidad. En la segunda, se retoma parte de un trabajo etnográfico realizado entre los años 2014 y 2018 con el objetivo de analizar los sentidos que el MFC recupera cuando es visitado por estudiantes y docentes (guiones, relatos de los encargados de las visitas, escenificación de objetos). La hipótesis consiste en afirmar que se distinguen seis entramados que constituyen una red de silencios que el Estado construyó sistemáticamente con el objetivo de justificar la extinción y el genocidio de los pueblos indígenas.
\end{abstract}

Palabras clave: Museo; Patrimonio; Memorias; Frontera; Silencios.

\begin{abstract}
In this article I analyze the processes of patrimonialization of the Fortín Cuatreros Museum (MFC) in Bahía Blanca (south of the province of Buenos Aires) and the associated historical narratives as processes of construction of local memories and educational resource for high-school students. This museum represents the last of the forts located in the advance of the frontier that guarded the so-called "Zanja de Alsina" in 1876, near the estuary that borders the city. In the first part of this article, the different frameworks that explain the meanings given to the present museum in historical perspective (foundation, patrimonial declarations, reconstructions) are displayed in dialogue with the stories of pioneer settlers of the town. In the second one, part of an ethnographic work carried out between 2014 and 2018 is taken up with the aim of analyzing the meanings that the MFQ recovers when visited by students and teachers (scripts, stories from those in charge of the visits, staging of objects). The hypothesis consists in asserting that six frameworks are distinguished, constituting a network of silence that the State systematically built to justify the extinction and genocide of indigenous peoples.
\end{abstract}

Keywords: Museum; Heritage; Memories; Frontier; Silences.

El juego de palabras del título, no intenta ser un trabalenguas sino una presentación de los procesos de patrimonialización estatal y sus usos políticos (Prats, 1997, 2005 y Ballart, 1997) asociados al Museo Fortín Cuatreros (MFC) basados en la construcción de un relato sobre la frontera y en los entramados de memorias con los que se relaciona. En este sentido, el concepto de activaciones patrimoniales de Llorenç Prats (1997) permite afirmar que el patrimonio se selecciona, no es una elección neutral y contiene afirmaciones discursivas que lo avalan en el tiempo. Pero éste discurso depende de los referentes escogidos, de sus significados, de la importancia que se le otorgue y del contexto, por lo tanto es una construcción social dinámica. Los bienes patrimoniales son portadores potenciales de un mensaje legítimo e instituido desde el poder hegemónico, pero son asimismo portadores de significados múltiples, muchos de los cuales permanecen en la esfera de la capacidad individual de los sujetos para 
experimentarlos (Gorosito Kramer, 2007, p. 209).

Actualmente, desde 1983, el MFC es un museo público de gestión municipal de Bahía Blanca y junto a otros seis museos, investigan, conservan y difunden el patrimonio cultural. El MFC se ubica en el partido de Bahía Blanca, pero está emplazado en la localidad de General Daniel Cerri, distante $15 \mathrm{~km}$ de la cabecera de dicho partido (Bahía Blanca) y depende administrativamente del Museo y Archivo Histórico de la ciudad. Para los pobladores y los historiadores amateurs, el edificio que hoy ocupa el MFC es el fortín original que dio origen al pueblo de Gral. Daniel Cerri. Esta asociación directa entre el fortín construido en 1876 y el edificio del actual museo ha sido fuente de disputas en términos de memoria y patrimonializaciones como analizaré más adelante.

La socióloga Elizabeth Jelin (2018), estudió los procesos de memorias vinculadas al pasado reciente en el Cono sur estableciendo que la memoria está constituida por las maneras en que los sujetos construyen un sentido del pasado en su enlace con el presente y también con el futuro. En este sentido, las luchas por establecer monumentos, museos, memoriales y placas recordatorias se despliegan abiertamente. Se trata de una materialidad con significado político, público y colectivo. Con respecto a su sentido político, afirma que al instalarse públicamente trae aparejada múltiples silencios sobre otros acontecimientos y otras interpretaciones políticas del pasado (2020, p. 456). Asimismo, las tramas del silencio exceden la materialidad de los monumentos, edificios, diarios, fronteras y censos para entramar procesos de producción y narrativas históricas (Trouillot, 2017, p. 23) en cuatro momentos: el de la creación del hecho (la elaboración de las fuentes); en el del ensamblaje de los hechos (la construcción de los archivos); en el de la recuperacióndel hecho (la construcción de narraciones) y el momento de la importancia retrospectiva del mismo.

En este artículo se despliegan en una primera parte, los distintos entramados que explican los sentidos otorgados al actual museo en perspectiva histórica y que referencian los dos primeros momentos (fundación, declaraciones patrimoniales, reconstrucciones) en diálogo con los relatos de pobladores pioneros de la localidad. En la segunda, se recuperan el tercer y cuarto momento. Metodológicamente, se retoma parte de un trabajo etnográfico realizado entre los años 2014 y 2018 con el objetivo de analizar los sentidos que el MFC recobra en las voces de los pobladores pioneros de la localidad de Cerri y en las visitas realizadas por estudiantes y docentes (guiones, relatos de los encargados de las visitas, escenificación de objetos). La hipótesis consiste en afirmar que se distinguen seis entramados que constituyen una red de silencios que el Estado construyó sistemáticamente con el objetivo de justificar la extinción y el genocidio de los pueblos indígena (Delrío y Ramos, 2011).

\section{Primera trama: el último fortín de la frontera y la espacialidad silenciosa de la memoria}

El fortín Cuatreros que da nombre al museo fue construido por instrucciones del Ministro de Guerra y Marina Adolfo Alsina en 1876 y fue el General Daniel Cerri el que se encargó de ejecutar dichas instrucciones en la margen izquierda del río Sauce Chico. La región que describe este artículo fue una frontera violenta en la cual el Estado nacional y el provincial establecieron diferentes políticas destinadas a someter a los pueblos indígenas que hasta fines el siglo XIX disputaron sus territorios de la región pampeana y patagónica (Lenton, 2010; Mases, 2010; Alioto, Jiménez y Villar, 2018); a la vez que se impulsaron políticas más estables de relaciones interétnicas con la sociedad indígena (Mandrini, 2008; Ratto 2015). Luego de las sucesivas campañas militares y el genocidio indígena se impuso el modelo agroexportador, diseñado en la región con el establecimiento en 1884 del puerto de Bahía Blanca (Ingeniero White) y una incipiente red ferroviaria que allí culminaba. En este contexto, a principios del siglo XX, la localidad de Cuatreros (luego Cerri) se destacó como un incipiente enclave industrial con el Frigorífico Sansinena y el lavadero y peladero de pieles Soulas et Fils.

Al concluir la Guerra con el Paraguay (1864-1870), el problema de la frontera sur comenzó a reverse cuando Nicolás Avellaneda llegó a la presidencia de la Argentina en 1874 y el problema indígena se tornó un tema central. En el contexto de una Argentina que atravesaba una profunda crisis económica, Avellaneda afirmaba que los límites productivos asociados a los asuntos agropecuarios tenía en la cuestión de la frontera un lugar preferencial y para resolverlo había que dejar de lado las expediciones punitorias y ocupar el territorio indígena (Mases, 2010). De esta manera, la cuestión de la ocupación de los territorios patagónicos se vinculó con el ejercicio del Estado sobre la soberanía nacional y los conflictos limítrofes con Chile que se intensificaron durante su presidencia.

En este contexto, la política de Adolfo Alsina como ministro de Guerra y Marina, significó un cambio importante en la estrategia sobre el tratamiento de las fronteras interiores y tuvo la finalidad de avanzar en líneas sucesivas hasta llegar al río Negro. En un momento inicial se implementó la construcción de diversos fuertes y fortines, que acompañarían a un largo foso, llamado la "Zanja de Alsina", en un eje que atravesaría desde el sur de la actual provincia de Córdoba hasta la ría de Bahía Blanca en el sur bonaerense.

A inicios del año 1876, Alsina propuso un plan de fortificar el río Sauce Chico, que constituía un límite natural del partido de Bahía Blanca, porque por ahí pasaban todos los "cuatreros" que arribaban ganado desde el sur de la provincia. El encargado de diseñar este plan fue el Teniente Coronel Graduado Daniel Cerri, quién estaba a cargo de la comandancia (Perrière, 2013) y organizó 
la construcción de la fortificación denominada Fortín Cuatreros en la culminación de una línea de frontera que finalizaba en los cangrejales próximos a la costa.

Si bien, la construcción original del Fortín Cuatreros aún no fue localizada arqueológicamente, a lo largo del tiempo, las políticas públicas y la población utilizaron al actual MFC como objeto para recordar y, por lo tanto, para entramar relatos y memorias sobre la frontera más allá de su "autenticidad". En base a las investigaciones realizadas por la historiadora y arqueóloga Alejandra Pupio (2013), quién analizó las distintas modificaciones por las que atravesó el edificio hasta su función como museo, se sabe que el MFC le permitió al Estado materializar los orígenes de la localidad de General Daniel Cerri aunque no sea el fortín original, sino una construcción de principios del siglo $X X$.

La materialidad invisible del fortín construido en 1876 constituye un silencio en la creación del hecho (Trouillot, 2017), sin embargo, es constitutivo de la fundación de la localidad. Esta materialidad invisible necesitó de una "visibilidad" en otro lugar que permita construir un nuevo relato fundacional y una narrativa que solape su ausencia. Esta narrativa recupera la función militar del fortín a la vez que cimienta un relato basado en la extinción y el genocidio indígena en el presente.

Qué se recuerda y qué se olvida son procesos que construyen memorias en el presente. Jelin (2018) exploró esta idea vinculada al pasado reciente en el Cono Sur, para ella el sentido del pasado está sujeto a interpretaciones y como tal se constituye a modo de un escenario de confrontación. La antropóloga Ana Ramos (2011) retoma estas ideas para destacar que los soportes reconocidos de la memoria (monumentos, archivos, relatos $u$ otros) no garantizan por si solos su evocación, sino en la medida en que estos son incluidos en acciones orientadas a traer el pasado al presente.

En este sentido, el MFC puede integrarse en lo que el historiador Mariano Nagy (2013) denominó en un artículo de esta revista: museos de frontera. Define a esta categoría, refiriéndose a un proceso común de fundación de museos basado en construcciones vinculadas a las campañas militares contra los indígenas, y que por esta razón asumen un discurso sobre la extinción del indígena caracterizado como "salvaje" o "bárbaro" y/o "extranjero". Su estudio se basó en el análisis de distintos museos que surgieron como expresión de la línea de frontera establecida por Alsina en 1876, entre ellos, los pertenecientes a las ciudades bonaerenses de Trenque Lauquen, Guaminí, Carhué y Púan.

Las políticas estatales a lo largo del tiempo, intentaron imponer una lógica oficial de memoria y una red de silencios como analizaré en los próximos apartados. En la década de 1940, el edificio que hoy ocupa el
MFC, estaba totalmente abandonado, sin embargo, fue declarado Monumento Nacionalpor la Comisión Nacional de Museos, Monumentos y Lugares Históricos (Decreto n. ${ }^{\circ}$ 14119). Esta situación de escombro(Gordillo, 2018) prosiguió durante treinta años, hasta que en el año 1974fue reconstruido como monumento/fortín por la Municipalidad de Bahía Blanca y por el Comando V Cuerpo del Ejército, adoptando paraello la disposición y materiales que se correspondían con lo que se suponía que había sido elfortín original (Pupio, 2012).

Por último, a principios de la década de 1980, se inician las tareas para convertir al edificio que simulaba al fortín en museo. El Museo Histórico y de Ciencias Naturales de Bahía Blanca se encargó de relevar su condición edilicia y peticionó al gobierno municipal el establecimiento de un museo; así fue como el 10 de septiembre de 1983 fue inaugurado el Museo Fortín Cuatreros y comenzó a recibir público.

\section{Segunda trama: El "escombro" es denominado "patrimonio moral de la Nación"}

Con la llegada a la presidencia de Roberto M. Ortiz (1938) y de su Ministro de Justicia e Instrucción Pública Jorge Coll en la Argentina, se produce un pronunciamiento estatal a favor de la fundación y el mejoramiento de los museos históricos del país. En este contexto, la Junta Histórica de Numismática Americana (JHNA), que había sido creada en 1893, se transformó en la Academia Nacional de la Historia, con facultades para supervisar el accionar de los museos históricos.

Asimismo, por decisión avalada por Ortiz en abril del mismo año se creó la Comisión Nacional de Monumentos, Museos y Lugares Históricos (CNMMyLH); tanto la Academia Nacional de Historia como la CNMMyLH fueron presididas por el historiador Ricardo Levene. A diferencia de otras legislaciones anteriores, la creación de esta Comisión Nacional tenía como finalidad considerar los lugares, museos, casas e iglesias como "patrimonio moral de la nación". La tarea primordial de los miembros de la CNMMyLH fue "proyectar la legislación nacional para unificar el contralor, administración, conservación de todos los lugares, monumentos, templos, casas y museos históricos del país" (Blasco, 2012).

Durante el año 1943, a poco tiempo de establecerse las finalidades de la CNMMyLH, se produce un golpe de Estado y en este contexto Edelmiro J. Farrel asume como presidente de facto, impulsando distintas peticiones que se realizaron desde el Ministerio de Guerra y Marina, y asimismo por los gobernadores de los Territorios Nacionales, con la finalidadde patrimonializar los lugares vinculados a las luchas de las fronteras de la segunda mitad del siglo XIX. Estos pedidos fueron derivados a la CNMMyLH, a fin de ser considerados comopatrimonio de la Nación. En este marco los fortines 
de frontera constituyeron una importante simbología asociada al avance contra los territorios que ocupaban las poblaciones indígenas. Al enfatizar la idea de las luchas de las fronteras se le otorga a la cuestión militar y a la materialidad de los fortines un rol preponderante silenciando, como contrapartida, el genocidio indígena.

Para Pupio (2013) esto demuestra la importancia que los temas militares, vinculados a la frontera de las últimas décadas del siglo XIX, estaban tomando en la historiografía argentina a partir de 1943.En este contexto, se iniciaron una serie de trámites para declarar al Fortín Cuatreros como Monumento Histórico. El trámite ante la CNMMyLH lo inicia el Ministro de Guerra y Marina, Edelmiro Farrel, a inicios de 1944, y en su argumento de fundamentación se asocia al fortín con la figura y trayectoria del General Daniel Cerri, destacando su participación en la Guerra del Paraguay. La CNMMyLH trató el pedido el 21 de marzo de 1944 y presentó una carta al Ministro de Justicia e Instrucción Pública para peticionar al Poder Ejecutivo que se considere al Fortín Cuatreros Monumento Histórico.

Por decreto n. ${ }^{\circ} 14119 / 44$ de junio de 1944 se declaró monumento histórico al Fortín Cuatreros y entre los argumentos se destacó la ubicación de su fundación: "Situado cerca de Bahía Blanca, en el pueblo del mismo nombre (General Daniel Cerri). Fundado por el general en el paso al poblado de Patagones, cuya actividad continúa en las Comandancias de Frontera y en la lucha contra el salvaje".

De esta manera, desde el Estado se entramaron distintas fuentes documentales y se silenciaron otras, para ensamblar los hechos y activar patrimonialmente a un edificio que se suponía había conformado la línea de frontera creada por Cerri en 1876. Al decir del antropólogo Michel Rolph Trouillot (2017) los archivos que se reúnen para justificar un hecho, son actos de producción activa para cimentar una inteligibilidad histórica. Estos archivos constituyen una materialidad legitimada e institucionalizada del proceso sociohistórico sobre la cual se construyen narrativas y ayudan a seleccionar las historias que importan (p. 43).

Sin embargo, otras fuentes históricas indican que la construcción donde actualmente se emplaza el museo cumplió funciones de casa azotea hasta la última década del siglo XIX, en que fue abandonada (Pupio, 2013).Con motivo de la declaración como monumento histórico, aparecieron las primeras fotos del edificio en el diario local La Nueva Provincia, con la leyenda: "Lo que queda en pie del Antiguo Fortín Cuatreros que acaba de ser declarado monumento histórico por el Gobierno de la Nación" (La Nueva Provincia, BahíaBlanca, 26 de junio de 1944, p. 11).

En este sentido, para el antropólogo Gastón Gordillo, los escombros permiten desestabilizar las ideas estetizadas que tenemos de las ruinas, sobre todo aquellas que son patrimonializadas. Por lo tanto, los escombros conllevan una crítica a la ideología de la ruina porque ve en ellos la sedimentación de los procesos de violencia y declinación antes que objetos de contemplación (2018, p. 25). Además, esos objetos constituyen una espacialidad de lugares habitados por prácticas y percepciones humanas en el presente; pero es una presencia definida por sensibilidades dominantes y para estudiarlas hay que ver las grietas que dichos escombros presentan.

Durante el trabajo de campo, en el año 2015, entrevisté a un poblador "pionero" de la localidad de Cerri, cuya familia fue propietaria del terreno y del edificio que actualmente ocupa el MFC. Él recordaba que a mediados del siglo XX, dicha construcción estaba muy deteriorada pero habitada:

H (Hernán): - ¿Cómo era el paisaje? ¿Qué recuerda? [En referencia a actual museo] P (Poblador): - ¿Qué yo lo haya visto? $\mathrm{H}$ : - Si, si!

P: - En la década del 1950, más atrás no te puedo hablar... Es lo más atrás que te puedo hablar: década del $1950 \ldots$ y ahí esto era... En realidad para describírtelo tengo que decirte algo que vos también lo sabes... esto fue dado allá por el 40, el 50 fue dado a Monumentos Históricos y todas esas cosas, años más años menos... no me acuerdo bien... (...) Mi nono, me acuerdo, le dio a una familia acá para que viva... Él no tenía potestad para darle [por ser Monumento Histórico Nacional] pero le dijo: ubíquense ahí, porque nadie se ocupaba de esto... Entonces yo me acuerdo que había una familia acá... $\mathrm{H}:-$ ¿ En el museo? P: - ¡No! Ustedes lo llaman Museo. Pero esto, en la década del 50 era... un pedazo de ladrillo con un techo deteriorado y había una familia de escasos recursos que vivía ahí... (Entrevista a poblador de Cerri, Gral. Daniel Cerri, 3 de junio, 2015)

El testimonio del poblador expresa que sus recuerdos se remontan hacia la década de 1950 cuando era niño, pero no vivía en ese lugar, sino que entrama su relato con la memoria de su abuelo ("nono") cuando cedió la construcción, ya patrimonializada, a una familia en situación de vulnerabilidad. Luego relata, que lo que recuerda del actual MFC es una construcción muy deteriorada que nada tenía que ver con lo que es el museo en la actualidad. A partir de su testimonio, se puede afirmar que en la década 1940, la construcción 
estaba abandonada y que luego fue ocupada por una familia con autorización de los propietarios del terreno. Más adelante analizaré la donación que los propietarios realizan del terrero a la municipalidad.

La construcción del relato del poblador de Cerri permite pensar los relatos y prácticas cotidianas de recordar que se transmiten en las relaciones sociales intergeneracionalmente, a la vez que van sedimentando lo que Tim Ingold (2011) denomina memorias-conocimientos. Se refiere a la memoria que se construye permanentemente entre los sujetos en un contexto determinado, pero que a su vez sintetiza todo el conocimiento integrado a lo largo de diversas trayectorias personales. De esta manera el conocer se constituye en un proceso activo de recordar, no como legado, sino como una actividad que construye memorias en el presente.

\section{Tercera trama: de "escombro" patrimonializado a un fortín imaginado}

Como mencioné anteriormente, el Fortín Cuatreros es el último fortín (el más cercano a la costa) de la línea de Alsina. Aunque el MFC actual no se corresponde con la construcción original de dicho fortín y su arquitectura no es igual a la del fortín planificado en 1876, su presentación como edificio patrimonializado reactualiza la idea sobre la importancia de las campañas militares y la "extinción de los pueblos indígenas".

La CNMMyLH determinó que la edificación que se declaraba como fortín estaba totalmente abandonada y correspondía a una tipología constructiva en ladrillos en forma de cuadrilátero característica de la última década del siglo XIX. Por lo tanto, su forma en nada se asimilaba a las construccionesfronterizas creadas en la década de 1870 en las márgenes del río Sauce Chico utilizadas para estabilizar la frontera y el potencial defensivo en un área inestable de la frontera.

Pupio (2012) estudió que los fortines construidos entre 1876 y 1877 fueron circulares,y así lo referencia Cerri en su Memoria enviada al Ministerio de Guerra en 1877. Esto permite pensar que, más que una "verdad histórica", el edificio declarado como monumento nacional refleja los intereses de quienes quisieron materializar espacios que reflejen procesos históricos conflictivos y violentos, en definitiva constitutivos de una historia militar y portadores de memorias.

Esta lógica se vuelve a manifestar durante el proceso de reconstrucción del Fortín Cuatreros por parte del V Cuerpo del Ejército, inaugurado el 9 de diciembre de 1974, en laque participó también el Museo Histórico y de Ciencias Naturales de Bahía Blanca. En ese momento un cartel sobre la calle del museo anunciaba que, además del ejército y el museo bahiense, colaboraron el Frigorífico CAP-Cuatreros, el Sindicato de Empleados de Industria de la Carne, el concejal de Bahía Blanca Don Celso Virgili, transporte "Don Juan",transporte "El Cholo", la Cooperativa de Transporte "12 de octubre" y la población de General Daniel Cerri a través de la Sociedad de Fomento y Cultura.

Un día antes a la inauguración, el diario local La Nueva Provincia daba cuenta de los trabajos realizados, reafirmando el binomio civilización-barbarie y ubicando a los militares como garantes del primer término y legitimando a las fuerzas armadas: "El V Cuerpo Entrega a la Comuna El Fortín Cuatreros: Un Vigía del Desierto. Como un vigía en el desierto - igual que hace casi 100 años se erige nuevamente, junto al arroyo Sauce Chico, el Fortín Cuatreros. Parecía que acababa de despertar de un largo sueño para renovar su función protectora" ( $L a$ Nueva Provincia, 9 de diciembre de 1974, p. 2).

En este sentido, los archivos que recordaban las construcciones circulares de los fortines en la Memoria de Cerri, que fueron silenciados cuando se lo declaró bien patrimonial, vuelven a recobrar sentido en la década de 1970. La reconstrucción implicó además, una serie de operaciones selectivas (Trouillot, 2017, p 44): selección de quienes son los productores de la historia (diversos integrantes de Estado), de la evidencia (en este caso el archivo documental), la elección del tema (lo militar en la frontera), la selección de los procedimientos a seguir, lo que significa en el mejor de los casos determinar el rango de importancia y en el peor, la exclusión de algunos productores, de alguna evidencia, de algunos temas, o de algunos procedimientos.

Los procedimientos, el rango de importancia y la exclusión de algunos productores de la historia se despliegan cuando los escombrosde la vieja casa en mal estado se reconstruyen simulando un fortín imaginario estetizado como los de fines del siglo XIX. De esta manera se amalgaman a la construcción de casa azotea en forma de cuadrilátero, un mangrullo, una empalizada, una pirca de palos y una zanja en forma de collage.

Sin embargo, para su reconstrucción, además de la participación del Ejército (en un contexto de auge del movimiento obrero y de la militancia armada) se involucraron redes políticas, empresariales y sindicales que retomando los argumentos de fines del siglo XIX, intentaron revalorar la "misión civilizadora" como fuente del desarrollo del Estado-nación-territorio argentino frente al "indígena malonero" (Delrio y Malvestitti, 2018).

Esta idea "civilizatoria" se resignifica en discurso del Teniente Coronel Ballofet en el acto de entrega del fortín luego de su reconstrucción: "La conservación del patrimonio cultural y material que fundamenta nuestras más claras tradiciones de hidalguía, de amor a la Patria, de vocación de servicio (...) y la comunidad de propósitos en cuanto a llevar a los conciudadanos que se dedican 
a consolidar el desarrollo nacional, la tranquilidad de su seguridad, así como los fortineros que vivieron y murieron lo hicieron hace un siglo" (La Nueva Provincia, 10 de diciembre de 1974, p. 2).

El rescate de lo militar, desde fines de la década de 1960 y hasta el inicio de la última dictadura militar argentina (1976-1983), fue una política pública constante en los pueblos y localidades de la provincia de Buenos Aires con la intención de silenciar la presencia indígena en el pasado regional. A diferencia de los sitios de la memoria referidos a la última dictadura militar que en la Argentina son relevantes como arquitecturas del recuerdo cuya intención según la antropóloga Ludmila Da Silva Catela (2014) es imprimir la idea de un patrimonio que es de todos, valorizando y abriendo al público los lugares en los cuales la violencia política dejó sus huellas; en los museos de frontera, por el contrario, se revaloriza las campañas "civilizatorias" militares contra los indígenas.

\section{Cuarta trama: nueva declaración patrimonial y viejos fundamentos}

Con el paso del tiempo el MFC recibe una nueva declaración como Monumento Histórico de la provincia de Buenos Aires en 1997, según Decreto n. ${ }^{\circ}$ 116/1997. Los fundamentos de esta declaración se expresaron en el proyecto de la Ley n. ${ }^{\circ} 11918$ presentado por la senadora Alicia Fernández de Gabiola y aprobado por la legislatura de la provincia el 18 de diciembre de 1996. La característica más importante de esta declaración es que dichos fundamentos mantienen los argumentos centrales de la declaración de 1944, pasado más de medio siglo después.

Los fundamentos se inician con un relato histórico que se remonta a las últimas décadas del siglo XIX, la alusión a las tareas que desarrolló el Dr. Nicolás Avellaneda durante su presidencia en la "guerra contra el desierto o la guerra de fronteras" que "generaban terror a las poblaciones" y el rol del ministro de Guerra A. Alsina "para ocupar de forma permanente la frontera". En este contexto es designado D. Cerri "quien se había destacado como héroe de la lucha contra el indio durante la invasión a Bahía Blanca en 1859" para la construcción de 13 fortines, siendo el primero de ellos el Fortín Cuatreros". Luego continúa relatando que el Fortín Cuatreros "reseña un robo de hacienda cometido por los indios invasores acto que dio nacimiento al nombre Paso de los Cuatreros", que Cerri sintetizó como "Cuatreros".

Los fundamentos continúan con las declaraciones patrimoniales anteriores (1944) "en las tierras donde se construyó el Fortín Cuatreros", el traspaso del inmueble a la municipalidad de Bahía Blanca en 1972 para su posterior reconstrucción a cargo de la Subsecretaría de Cultura y bajo la dirección del Museo Histórico y de Ciencias Naturales. Sobre esta donación, el poblador de Cerri, cuenta que en la década de 1970, su familia donó algunas hectáreas que rodeaban el fortín y que actualmente conforman su paisaje circundante:

Después se hizo una donación, mi familia la hizo de forma notarial y allá por el 1971, 1972. (...) No de ese pedacito del fortín, porque no tenían facultad para hacerlo, no se puede donar el arroyo. [En relación con que el patrimonio es un bien del Estado]. Pero si de todo este pedazo, porque todo este pedazo era la quinta, hasta acá donde estamos sentados. Todo este pedazo fue donado (...) En definitiva eso es patrimonio nacional, municipal, y provincial pero el pedazo, alto, largo y ancho digamos, pero ya salís un metro de ahí y ino! Es por eso que mi familia donó este pedazo (Entrevista a poblador de Cerri, Gral. Daniel Cerri, 3 de junio, 2015)

Retomando la entrevista al poblador de Cerri, él menciona una segunda donación, esta vez al municipio, del predio que rodea al actual MFC. En su relato se superponen distintos soportes sobre los procesos de patrimonialización del edificio: "el pedazo: alto, largo y ancho" que fueron declarados patrimonio nacional y provincial en distintas etapas.

Por último, la declaración del MFC como monumento histórico provincial en 1997 menciona la importancia que se le otorgó al fortín en el contexto de la sanción de la ley provincial: "Hoy, el Fortín, reconstruido, rehabilitado en su primitiva forma constituye un monumento histórico, un homenaje a lo que fue él mismo y a lo que significaron los hombres que se brindaron con él en aquella gesta civilizadora" y "pilar fundamental para consolidar la identidad de los bonaerenses, identidad que debe construirse día a día enalteciendo la historia, lo que coloca a la comunidad en condiciones de unidad espiritual para analizar juntos los problemas del presente y proyectarse con esperanza hacia el futuro" (https:// intranet.hcdiputados-ba.gov.ar/includes/ley_completa. php?vnroley=11918)

Para Trouillot (2017) las presencias y las ausencias incorporadas en las fuentes (artefactos y hechos que convierten un acontecimiento en un hecho) o en los archivos (hechos recogidos, tematizados y procesados como documentos y monumentos) no son neutrales ni naturales. Hay un compromiso estatal en la práctica del silencio, las menciones y los silencios son activos y son inherentes a la Historia y demuestran los límites para la reconstrucción exacta del pasado como analizaré en el siguiente apartado. 


\section{Quinta trama: la escenificación del pasado en el MFC}

El patrimonio de los museos no se restringe a sus edificios, sino también a la materialidad de los objetos, y a como son entendidos en el marco de diferentes narrativas expresadas a modo de teatralidad. Al decir de Néstor García Canclini (1990) la teatralización del patrimonio es el esfuerzo por simular que hay un origen, se celebra el patrimonio histórico constituido por los acontecimientos fundadores, los héroes que los protagonizaron y los objetos fetichizados que los evocan. En los museos, se exhiben objetos, sobre los cuales se construyen ideas sobre el pasado en disputa (Crespo, 2005).

En este apartado me interesa señalar como el MFC reivindica la figura militar del General Cerri. Siguiendo a García Canclini mostraré cómo el patrimonio histórico está constituido por acontecimientos fundadores, los héroes que los protagonizaron y los objetos fetichizados que los evocan (1990, p. 153). Considero que en el MFC en general y en la Sala "Cerri" en particular, se fortalece una visión histórica oficial basada en la historia militar, que es la que funciona como articuladora del relato. De esta manera, se enfatiza la presencia militar en la región y se resignifica en el presente la idea de lucha de las fronteras para justificar el genocidio indígena y como consecuencia su "extinción".

Al parque que rodea al museo, se ingresa atravesando una empalizada horizontalsimulando un puente levadizo. EI MFC tiene forma de cuadrilátero irregular, de paredes pintadas de rosado y grandes ventanales verdes, lo rodea un área verde arbolada. Un mangrullo alto de madera se eleva sobre un costado del patio, como símbolo característico de los fortines.

En el interior del museo hay un depósito y tres pequeñas salas abiertas al público. Una de ellas, la de mayor tamaño, estaba dedicada durante la investigación (2014-2018) a la vida del General Daniel Cerri y es la que analizaré en profundidad en este artículo. Ésta sala se instaló en el año 2014, para la conmemoración de los cien años de su fallecimiento: es una sala cuyo eje es recuperar los aspectos biográficos de su carrera política y militar, su colaboración con otras instituciones bahienses como la Biblioteca Rivadavia y el Hospital Municipal, y su rol de novelista.Tiene una forma rectangular, con una puerta de acceso en uno de sus lados.

En el interior del MFC, los objetos, banners e imágenes se refieren mayoritariamente a la vida militar del general Daniel Cerri, se destaca su rol en la "defensa de la patria" y se lo constituye como una figura militar a nivel nacional. En este sentido, en el relato se describe su participación en la LegiónAgrícola Militar (1858-1859) ${ }^{1}$ y su desempeño

1 La Legión Agrícola Militar o Colonia Militar fue un proyecto económico y militar impulsado por el gobierno provincial en 1856. Tuvo como finalidad la realización de tareas agrícolas y la defensa de la frontera. En la región se estableció entre los años 1856 y 1858 en la en la defensa de Bahía Blanca frente al malónde 1859 (Perrière, 2020)², la intervención en la Guerra del Paraguay (1864-1870) y la creación del Fortín Cuatreros (1876) como Jefe de Frontera, fortificación que dio origen a la actual ciudad deGeneral Daniel Cerri. ${ }^{3}$

Al entrar los visitantes se encuentran con una primera vitrina central en forma de caja transparente que contiene un busto de costura con el uniforme militar de Cerri. Sobre la pared del fondo y las laterales también se encuentran tres vitrinas que incluyen armas, piqué, medallas militares, sus dientes, espadas, una maqueta del barco en el que llegó a Buenos Aires, banderas de los regimientos, un retrato de Cerri y otro muñeco con traje militar. El énfasis en lo militar materializado en los objetos contrasta con las pocas referencias vinculadas a los pueblos indígenas. Una de ellas es un mapa actual de la provincia de Buenos Aires donde se marca la ciudad de Pigüé, en referencia a la batalla del mismo nombre en la que triunfa Calfucurá (1858) ${ }^{4}$, la intención de esta imagen es demostrar el poderío que en la región tenía Calfucurá que un año después impulsaría el gran malón a Bahía Blanca que culminó con la masacre indígena. Otra referencia se encuentra en un banner que describe "El nombre de Paso de los Cuatreros" en él se menciona que su nombre se debe a: "la invasión o más bien un golpe de mano, que unos 300 indios nos dieran un 27 de mayo, a eso de la una del día que utilizó [en referencia a Cerri] como punto que llamó Paso de los Cuatreros".

En septiembre del 2014 se agrega una placa con un escudo militar con el diseño de su rostro coronado por laureles que menciona todas las batallas en las que participó, un sable y algunos documentos históricos sobre sus ascensos militares, todos objetos que ingresan al MFC por una donación de la familia. En el transcurso del trabajo de campo participé de este acto de donación que realizó el bisnieto del general Cerri al MFC el 18 de septiembre de 2014. Para este acto se realizó una importante celebración

margen izquierda del río Sauce Chico y se llamó Colonia Nueva Roma. 2 El Malón 1859 a Bahía Blanca fue impulsado por el cacique Calfucurá. Entre las fuerzas que defendieron al poblado, se encontraban integrantes de la Legión Italiana y de la Guardia Nacional. Luego de ser derrotados, los cuerpos de los indígenas muertos fueron quemados a la vista de todo el vecindario. La presencia de Calfucurá en la región se registra desde 1832 cuando un contingente de indígenas transcordilleranos llegaron a las cercanías de Bahía Blanca. Su predominio en la región fue indiscutido hasta la década de 1870 cuando su confederación indígena se comienza a disgregar por las políticas de negociación del Estado nacional. Para ampliar consultar: de Jong, 2009.

3 Esta intención de destacar la cuestión militar en los museos de frontera fue estudiada por M. Nagy (2013) quien da cuenta de la trayectoria del general Villegas en la fundación de Trenque Lauquen y su representación en el museo local. Estos casos son relevantes ya que las campañas militares son parte ineludible del origen de las ciudades en el suroeste de la provincia de Buenos Aires, y sus protagonistas principales se incorporaron como personajes que merecen pleitesía y homenajes locales.

4 Sobre el triunfo de Calfucurá en esta batalla hay un debate historiográfico sobre quien fue el o los vencedores y si fue realmente una batalla o la comunidad se retira del lugar antes de la llegada de las tropas nacionales 
en la que participaron el intendente, autoridades del municipio, concejales, senadores y la directora del Museo y Archivo Histórico de Bahía Blanca, entre otros.

La imagen del paisaje periurbano, las calles de tierra y los altos árboles generan el clima adecuado para que el encargado de las visitas explique que, el MFC es un museo que representa un viejo fortín que mandó a construir el general Cerri bajo las órdenes de Alsina en 1876. Cruzar por el "puente elevadizo" y visualizar un gran mangrullo de madera también es una muestra material de un espacio demarcado que produce silencios. Asociado a este relato introductorio, el guía advierte que el edifico es patrimonio nacional y provincial como describiré en el siguiente apartado.

El patrimonio de los museos va entonces más allá de la preservación de lo material, ya que a través de sus objetos propone acontecimientos, hechos y territorios para recordar. Es legitimador de ciertas ideas y narrativas, validando algunas memorias por encima de otras. En el MFC se exhibe un relato que justifica a través de su patrimonio y de las narrativas, el genocidio indígena y las campañas militares en el sudoeste bonaerense.

En este sentido, la trama del silencio oculta un periodo de relaciones interétnicas entre los pueblos indígenas y las poblaciones criollas en la región y las formas de vida indígenas prehispánicas. En el siglo XIX, las relaciones interétnicas estaban constituidas por: un circuito de intercambios de bienes en los poblados fronterizos, acuerdos y pactos sobre las incursiones territoriales, negociaciones comerciales y episodios violentos como fueron las campañas militares además de los malones, únicos hechos en los cuales se hace referencia a la presencia indígena en la región.

\section{Sexta trama: el patrimonio edificado, lo militar y el genocidio como recurso narrativo en las visitas escolares}

Anteriormente me referí al caso del MFC y su denominación como Monumento Histórico Nacional en 1944, momento en que el edificio se encontraba en estado de total abandono;ahora recuperaré del trabajo de campo las referencias a lo que suele acontecer durante las visitas escolares.

La propuesta educativa del MFC se estructura en un relato conducido por los guías; a continuación, describiré las visitas y el rol de ellos, ya que son quienes desarrollan una explicación minuciosa de la vida de Cerri, apoyándose en determinados objetos (que he descripto en el apartado anterior) que sirven como disparadores para explicar hechos políticos locales y nacionales. En sucesivas conversaciones informales con los encargados de las visitas, era común que ellos mencionaran que abordaban la muestra de una manera que llamaban "Cuatrereando historias", que consistía en empalmar y contar historias de la región y de Bahía Blanca. En estos relatos se construye la imagen de Cerri como "héroe de la patria", como "el italiano que más sangre argentina tenía", entre otras imágenes que aluden a la nacionalidad.

Al MFC acompañé a dos escuelas secundarias: la Escuela Federal en el año 2014 y la Escuela Noroeste en $2015^{5}$ a sus respectivas visitas a las que haré referencia en este apartado. En ambas visitas (y en otras que he observado y mencionaré brevemente) el relato del encargado es similar, ni bien llega el contingente, afuera del museo, se inicia el relato que da cuenta del edificio patrimonializado:

Bienvenidos a Fortín Cuatreros... les cuento qué es este lugar a donde vinieron... esta es una casa fortaleza de 1876, lo conocemos como MuseoFortín Cuatreros, este es el segundo Fortín Cuatreros, el primero estaba ubicado casi sobre los cangrejales en la costa... tenía la función de proteger la zona dado que por estos caminos se daba que venían malones a robar ganado y a hacer saqueos... Entonces, por aquellos años, el General Cerri decidió fundar una línea de fortines que llegaba hasta Córdoba y este (por el Fortín Cuatreros), era el primero de toda esa línea...

¡Bueno, bienvenidos! Esun museo histórico nacional y provincial tiene una importancia por su antigüedad y por los hechos que acá sucedieron [...] La importancia de nuestro museo a pesar de que es chiquito es el edificio histórico en si... este pequeño edificio es monumento histórico nacional desde 1944 y es monumento histórico provincial también. Por eso la importancia en sí del edificio" (Visita de $6^{\circ} \mathrm{A}$ y $\mathrm{B}$ al MFC, Escuela Noroeste, Gral. Daniel Cerri, 3de julio 2015).

Como se desprende de estos fragmentos, el encargado de las visitas realiza la presentación del edificio al iniciarlas. En las mismas, superpone distintas referencias: a)que es una casa-fortaleza de 1876 (año de la fundación del Fortín Cuatreros), y b) que el museo sería un "segundo" fortín porque el primero estaba más cerca de la costa. Este relato intenta asimilar dos construcciones diferentes: la casa azotea (actual museo) y el fortín que mandó a construir Cerri.

En su relato, aunque aclara que no es el fortín original, que se ubicó en los "cangrejales de la costa", los argumentos

\footnotetext{
5 Los nombres de las escuelas son ficticios para preservar su identidad, al igual que el de las y los demás actores que formaron parte de la investigación.
} 
presentados son los mismos que se utilizaron para la fundación del fortín "Cuatreros": "protección frente a los malones que robaban ganado y saqueaban" y esto sería la justificación para "fundar una línea de fortines". Argumentos que se reponen como sedimentos en todas las declaraciones patrimoniales, marcando un contínuum argumentativo por parte de Estado y algunas de sus instituciones por más 140 años.

En la sala del General Cerri, el encargado de las visitas desarrolla una serie de temas históricos apoyado en el patrimonio de la sala, de los cuales seleccionaré algunos especialmente relevantes para analizar: la vida militar de Cerri y la presencia de los pueblos indígenas. En el tratamiento de estos temas se fortalece un relato donde la violencia va a constituir un elemento central.

La selección de algunos fragmentos de los registros de campo permite analizar la construcción del relato militar que no se circunscribe al sudoeste bonaerense. En este contexto y asociadas a este relato, se presentan las propuestas que desde el MFC dan cuenta de la presencia indígena pero que son "nocivas", "feroces" y "violentas", destacando como contrapartida la "conquista" estatal y militar del territorio.

En la visita de la Escuela Noroeste, un estudiante preguntó si Cerri era italiano, a lo que el guía de visitas le respondió: "Sí, nació en Italia, pero dijo que tenía sangre argentina porque todas sus peleas las hizo como tal" (Registro de visita de Escuela Noroeste al MFC, General Daniel Cerri, 3 de julio 2015). En otra visita pude registrar los fundamentos que el encargado mencionaba para justificar su "sangre argentina":

Una de las cosas que va a hacer Cerri, es participar de la Guerra del Paraguay (...) En la primera batalla que va a tener la Argentina va a participar Cerri, va a ser la recuperación de Corrientes (...) Cerri va a participar y va a tener un hecho heroico, porque antes las batallas se ganaban por las banderas (...) Cerri se mete en campo del enemigo y recupera la bandera argentina y le dan un ascenso por el valor heroico de haber recuperado la bandera en campo enemigo (Visita de $5^{\circ} \mathrm{B}$ de la Escuela Federal al MFC, 8 de septiembre de 2014)

Durante las visitas observadas el rol del encargado ocupó un lugar central, articulando en sus narrativas hechos históricos, anécdotas e interpretaciones personales que relató deforma expresiva, acaparando la atención del público escolar. Este relato en ambas visitas se extendió por alrededor de 45 minutos en un recorrido por la sala que comienza desde la izquierda hacia la derecha. El relato del guía propone recuperar la biografía de Cerri desde su llegada a la región en 1858 hasta la finalización de su carrera militar en 1903. Al iniciar la charla, el encargado menciona que la idea del recorrido es contar la historia de quién fundó el fortín, el General Daniel Cerri:

Siempre contamos que Cerri vivía en Bérgamo, norte de Italia (...) y a los diez años, viene a la Argentina (...) En la costanera de Buenos Aires, entra a un bar, se da cuenta de que el menú estaba escrito en italiano y se encuentra con un par de soldados italianos, en el lugar. Entonces les pregunta que hacen dos italianos en el puerto de Buenos Aires y le cuentan que son parte de una legión agrícola militar (...) y Cerri se suma a la legión y se viene a Bahía Blanca (Visita de $5^{\circ} \mathrm{B}$ de la Escuela Federal al MFC, 8 de septiembre de 2014).

En otro artículo (Perrière, 2020) hice referencia a otro suceso en el que el encargado de las visitas hizo referencia a la participación del General Cerri en la defensa del poblado de Bahía Blanca, cuando se produjo el malón de 1859, que culminó en la matanza y quema de 150 indígenas en la plaza central. El hilo argumental que sostenía el relato fueron las cuestiones higiénicas: "hay mucha gente que habla muy mal de ese malón, pero en realidad nosotros éramos un grupo de soldados acá, nos defendimos y los quemamos... era una cuestión higiénica, si vos no los quemabas te enfermabas" (Vista de $5^{\circ} \mathrm{B}$ de la Escuela Federal al MFC, 8 de septiembre de 2014).

En una de las visitas registradas en la que participaron estudiantes de los profesorados de educación primaria e inicial junto a sus docentes, el encargado de las visitas aclaró luego de hacer referencia al malón de 1859 y sus consecuencias, que Cerri había participado con la "bayoneta en la defensa del poblado"pero que denunció la quema: "Cerri, es uno de los que denuncia la quema de cuerpos, por eso también es muy importante... Además es el que mejor hace todo el registro histórico de toda la batalla" (Visita Magisterio al MFC, 19 de mayo 2015)

Por último, me interesa destacar cómo en el relato del MFC hay una reiterada justificación del genocidio indígena. En el siguiente fragmento presento la descripción que realizó el encargado de las visitas sobre la participación de Cerri en la llamada Conquista al Desierto impulsada porRoca:

Encargado (E): - ¿Alguien se acuerda algo de la Conquista al Desierto?... [Los estudiantes responden que no] ¿Alguien tiene un billete de 100 pesos que me preste?...[Murmullos]

Docente (D): - ¿Vuelve? [En relación a si será devuelto]

E: - ¿En serio? Nadie tiene un billete de 
100 pesos...

D: - Si yo [busca el billete de su billetera en la cartera y se lo da]

E: - En el billete de 100 pesos está Julio Argentino Roca... del otro lado está la Campaña al Desierto [levanta el billete] AAA (alumnos): - Ahhh, mira! (...)

E: - Parece que este Roca, que era bastante inteligente, busca dinero y mata a todos los indios (...) durante la Conquista al Desierto, Cerri era comandante de frontera y participó... Pero le pide a Roca personalmente porun escrito, no ir al campo de batalla y ser Jefe de Detall (sic)... es decir estar acargo de los pertrechos, las armas y demás... Pero no va a estar en el frente deba talla porque sabía que iba a ser una sangría... sabía que iban a matar indios a lo pavo. (Registro de visita de la Escuela Noroeste al MFC, General Cerri, 3 dejulio 2015).

Este relato se apoya en una de las tantas fotos tomadas por Antonio Pozzo, previas y durante la Campaña al Desierto, para explicar la participación de Cerri en la misma. El guía estaba relatando la carrera militar de Cerri remitiendo a distintos objetos, pero, para explicar la expedición de Roca, apela a la descripción del billete de \$100 para concluir que Cerri participó de la Campaña sin estar en el campo de batalla. Sin embargo, el relato podría haber concluido ahí ya que se había mencionado la participación de Cerri, pero continúa para explicar la estrategia de "matar indios a lo pavo" de Roca a quién lo menciona como "bastante inteligente". Si bien en las visitas observadas, frente a estos relatos, hay miradas entre estudiantes y docentes, a veces gestos de repudio a lo dicho o expresiones como " ${ }_{\mathrm{iNo}}$ !..." el relato intenta un discurso que unifique en "un nosotros" la defensa de la Nación frente a los conflictos internos.

Inscripto dentro de una narrativa militar nacionalista, se vuelve a enfatizar el rol asumido por Cerri en una campaña militar encargada de "matar indios", aunque destacando que Cerri solicitó no estar en el campo de batalla. Esterelato sobre las campañas militares que incluye, pero a la vez desliga al héroe de las atrocidades remite a las "guerras" como un evento épico que permite que sus consecuencias sean interpretadas como consecución lógica de un triunfo sobre un enemigo asociado al mundo salvaje (Delrio y Malvestitti, 2018). Se retoma en la práctica del narrar, los mismos argumentos que justificaron las declaraciones patrimoniales.

En este sentido, en el MFC se produce lo que Nagy (2013) describió para otros museos de frontera: un relato de abnegación y sacrificio por parte de los pioneros inmigrantes que, atemorizados por el latente ataque de los "salvajes" y "bárbaros" pueblos indígenas, son defendidos por el ejército. Los "indios" son mencionados como el origen del problema y los responsables de los ataques que debieron ser repelidos por aquellos hombres nobles que pretendían poblar la llanura bonaerense ( $p$. 89).

Los silencios (y no olvidos) en los guiones museográficos, fueron abordados por Carolina Crespo y Alma Tozzini (2014) en la propuesta del Museo Regional de "El Hoyo" en la Comarca Andina (Patagonia, Argentina). Para las investigadoras, el abordaje de los silencios les permitió analizar los procesos de pertenencia, diferenciación y territorializaciones como campos de acción. En el caso de estudio, los relatos oficiales se impusieron resaltando la soberanía argentina en la región y la "blanquitud" predominante sobre otras formas identitarias. Además en las visitas guiadas del MFC se sintetiza y cimienta todas las tramas en una red de silencios dirigida mayoritariamente a un público escolar, son los momentos de la recuperación del hecho por sus narraciones y de la importancia retrospectiva de la producción histórica (Trouillot, 2017).

De esta manera, el silencio forzado, callado e impuesto opera invisibilizando a la población indígena y sus modos de vida en un contexto donde el museo funciona como la voz autorizada para difundir la memoria. Sin embrago, como analizan Crespo y Tozzini, estas narrativas sobre la memoria exceden a la institución museística y expresan un entramado de poder más amplio que incluye diversas esferas estatales con la intención de hegemonizar un discurso que justifique la "derrota" y posterior "extermino" de los pueblos indígenas. A la vez que operan destacando otros sujetos como los migrantes, los militares y las elites políticas como sinónimo de progreso.

\section{Reflexiones finales}

Un elemento a mencionar en primer lugar, es que el nombre del museo: "Fortín Cuatreros" proyecta una idea de defensa u ofensiva sobre los pueblos indígenas en el sudoeste bonaerense. Por lo tanto, al MFC se lo puede considerar un museo de frontera por ser parte de los museos de las localidades y pueblos que surgieron de la línea de frontera creada por el ministro de Guerra y Marina A. Alsina. Aunque a diferencia de la mayoría de estos, el patrimonio del MFC es histórico y no contiene piezas arqueológicas referidas a las poblaciones indígenas, sino que el discurso mantiene un silencio explícito sobre la forma de vida de los pueblos indígenas y las relaciones interétnicas.

En la activación patrimonial del MFC se pudieron analizar, al menos seis tramas que construyen una red de silencios que dan sentido al Fortín Cuatreros fundado en 1876 como producción histórica: "espacialidad silenciosa", "un escombro patrimonializado", "un fortín imaginado" y un "fortín escenificado". Sin embargo, más allá de la 
materialidad del edificio, también se asocian otras tramas narrativas basadas en los archivos y en las políticas institucionales que sedimentaron a lo largo del tiempo discursos hegemónicos de memoria sobre la presencia militar y su "heroica guerra contra el indio" en el presente.

En este sentido, las narrativas producidas por el encargado de las visitas, las declaraciones patrimoniales (1944 y 1997), la escenificación del fortín y el guión y los objetos del MFC, pueden pensarse como tramas de memorias que en el nivel local y municipal reorganizan el estereotipo fundante de la Nación argentina, el de una población homogénea y blanca, silenciando a los pueblos indígenas. Cuando se los menciona, se lo hace con una imagen negativa, se acentúan los malones como instancias de invasión y su crueldad; mientras que se destaca la presencia militar en la figura de Cerri centralmente, pero también en la de Julio Argentino Roca en el siglo XIX. Esta presencia militar se reactualiza con la reconstrucción del fortín que, si bien carece de "autenticidad", el discurso asociado tiene una fuerte impronta nacionalista.

Las imágenes que se relatan en el guión del museo frente a un público estudiantil, que mayoritariamente visita los museos, también tiende a fortalecer una visión militarista de la frontera. Pero esta impronta no puede ser pensada de forma aislada de todo un entramado sostenido por distintas esferas del Estado a lo largo del tiempo, aunque hoy sean predominantes en parte de las políticas culturales y los museos del Municipio de Bahía Blanca.

Bahía Blanca, 25 de septiembre de 2020

\section{Agradecimientos}

Al personal del Museo Fortín Cuatreros. A Ixs evaluadorxs por sus comentarios y sugerencias que me permitieron mejorar este artículo.

\section{Bibliografía}

Alioto, S., Jiménez, J.F. y Villar, D. (2018). Devastación: violencia civilizada contra los indios de las llanuras del Plata y Sur de Chile: siglos XVI a XIX. Rosario: Prohistoria Ediciones.

Ballart J. (1997). El patrimonio histórico y arqueológico: valor y uso. Barcelona: Editorial Ariel.

Blasco, M. E. (2012). De objetos a "patrimonio moral de la nación": prácticas asociadas alfuncionamiento de los museos en la Argentina de las décadas de 1920 y 1930. NuevoMundo, Mundos Nuevos, 00, 1-25.Recuperado de: https://journals.openedition.org/nuevomundo/64679

Cámara de Diputados y Senadores de la provincia de Buenos Aires (10 de enero de 1997). Declarando monumento histórico provincial al Fortín Cuatreros, ubicado en la localidad de general Daniel Cerri, partido de Bahía Blanca. [Ley n. ${ }^{\circ} 11918$ ]. Recuperado de https:// intranet.hcdiputadosba.gov.ar/includes/ley_completa. php?vnroley $=11918$

Crespo, C. (2005). ¿Qué pertenece a quién? Procesos de patrimonialización y PueblosOriginarios en Patagonia. Cuadernos de Antropología Social, 21, 133-149.

Crespo, C. y Tozzini, M. A. (2014). Memorias silenciadas y patrimonios ausentes en elMuseo Histórico de El Hoyo, Comarca Andina del Paralelo $42^{\circ}$, Patagonia Argentina. Antípoda, 19, 21-44. Recuperado de: https://ri.conicet. gov.ar/bitstream/handle/11336/3578/CONICET_Digital_ Nro.4738_D.pdf?sequence=5\&isAllowed $=y$

Da Silva Catela, L. (2014). Lo que merece serrecordado...". Conflictosy tensiones en torno a losproyectos públicos sobre losusos del pasado en los sitiosde memoria. Clepsidra. Revista Interdisciplinaria de Estudios sobre Memoria, 2, 28-47. Recuperado de http://ppct.caicyt. gov.ar/index.php/clepsidra/article/view/Da\%20Silva\%20 Catela

De Jong, I. (2009). Armado y desarmado de una confederación: el liderazgo de Calfucurá enel período de la organización nacional. Quinto Sol, 13, (11-45).

Decreto n. ${ }^{\circ} 14119$, (7 de junio de 1944). Anales de Legislación Argentina. Tomo IV. TerceraEdición. Buenos Aires: La Ley.

Delrio, W. D. y Ramos A. (2011). Genocidio como categoría analítica: memoria social y marcosalternativos. Corpus. Archivos virtuales de la alteridad americana, 1(2).Recuperado de https://journals.openedition.org/ corpusarchivos/1129

Delrio, W. D. y Malvestitti, M. (2018). Memorias del "awkan". En W. D. Delrio, D. Escolar, D. Lenton.y M. Malvestitti (Comps.). En En el país del nomeacuerdo. Archivos y memorias del genocidio del Estado argentino sobre los pueblos originarios, 1870-1950 (pp. 23-67). Viedma: Editorial Universidad de Río Negro.

García Canclini, N. (1990). Culturas hibridas: estrategias para entrar y salir de la modernidad. México: Editorial Grijalbo.

Gordillo, G. (2018). Los escombros del progreso: ciudades perdidas, estaciones abandonadas y deforestación sojera en el norte argentino. Ciudad Autónoma de Buenos Aires:Siglo Veintiuno Editores.

Gorosito Kramer, A. M. (2007). El patrimonio aborigen y los patrimonios oficializados. En C.Crespo, F. Losada y A. Martín (Eds.). Patrimonio, políticas culturales y participación ciudadana. (pp. 207-231). Buenos Aires: 
Antropofagia.

Ingold, T. (2011). Being Alive: Essays on Movement, Knowledge, and Description. London:Routledge.

Jelin, E. (2018). La lucha por el pasado. Cómo construimos la memoria social. CiudadAutónoma de Buenos Aires: Siglo XXI.

Jelin, E. (2020). Marcas territoriales, patrimonio y memoria.¿Conservar o transmitir?En L. da Silva Catela, M. Cerrutti y S. Pereyra (Comps)Las tramas del tiempo. Familia, género, memorias, derechos ymovimientos sociales (pp. 455-484). Ciudad Autónoma de Buenos Aires: CLACSO.

La Municipalidad recibió ayer el Fortín Cuatreros reconstruido por el ejército, (10 de diciembre de 1974). La Nueva Provincia, p. 2.

Lappas, A. (1958). La masonería argentina a través de sus hombres. Buenos Aires: Alcibiades Lappas.

Lenton, D. (2010). Presentación del debate: Genocidio y política indigenista. Debates sobre la potencia explicativa de una categoría polémica. Corpus. Archivos virtuales de la alteridad americana, 1(2). Recuperado de http://ppct. caicyt.gov.ar/index.php/corpus

Lo que queda en pie del Antiguo Fortín Cuatreros que acaba de ser declarado monumento histórico por el Gobierno de la Nación. (26 de junio de 1944). La Nueva Provincia, p. 11.

Mandrini, R. (2008). La Argentina aborigen. De los primeros pobladores a 1910.Buenos Aires: Siglo XXI Editores.

Mases, E. H. (2010). Estado y cuestión indígena: el destino final de los indios sometidos en elsur del territorio (1878-1930). Buenos Aires: Prometeo Libros.

Ministerio de Justicia y Derechos Humanos. (30 de septiembre 1940). Creación de la Comisión Nacional de Museos y de Monumentos y Lugares Históricos. [Ley $n$ - 12665]. Recuperado de http://servicios.infoleg.gob.ar/ infolegInternet/anexos/20000-24999/23121/texact.htm
Nagy, M. A. (2013). Los museos de la última frontera bonaerense y sus narrativas acerca de los pueblos indígenas. Revista del Museo de Antropología, 79-90. Recuperado dehttps://revistas.unc.edu.ar/index.php/ antropologia/article/view/5506

Perrière, H. (2013). El río sauce Chico como testigo de las estrategias implementadas durante la organización del Estado Nacional (1850-1890). En A. Pupio y H. Perrière. Malones, fortines y estancias en la identidad de General Daniel Cerri (pp. 61-90). Bahía Blanca: EDIUNS.

Perrière, H. (2020). Malón de 1859 a Bahía Blanca: memorias conflictivas destinadas a y producidas por estudiantes de la escuela secundaria. Corpus. Archivos virtuales de la alteridad americana 10 (1). Recuperado de: http://journals.openedition.org/corpusarchivos/3747

Pupio, A. (2012). Profesionales y aficionados en la conformación, interpretación y exhibiciónde las colecciones arqueológicas. Coleccionistas y museos de la provincia de BuenosAires. (Tesis de doctorado), Universidad de Buenos Aires, Facultad de Filosofía yLetras, Ciudad Autónoma de Buenos Aires, Argentina.

Pupio, A. (2013). El fortín Cuatreros en la conmemoración del pasado: ¿Qué historia(s) nohan contado? En A. Pupio y $\mathrm{H}$. Perrière. Malones, fortines y estancias en la identidadde General Daniel Cerri (pp. 13-47). Bahía Blanca: EDIUNS.

Prats, LI. (1997). Antropología y patrimonio. Barcelona: Editorial Ariel.

Prats, LI. (2005). Concepto y gestión del patrimonio local. Cuadernos de Antropología Social 21, 17-35.

Ramos, A. (2011). Perspectivas antropológicas sobre la memoria en contextos dediversidad/desigualdad. Alteridades 21(42), 131-148.

Ratto, S. (2015). Redes políticas en la frontera bonaerense 1836-1873: crónica de un final anunciado. Bernal: Universidad Nacional de Quilmes.

Trouillot, M. R. (2017). Silenciando el pasado. El poder y la producción de la Historia. Granada: Comares Editorial. 